Supporting Information for

\title{
Reversible control of spintronic properties of ferromagnetic metal/organic interfaces through selective molecular switching
}

Sha Yang ${ }^{1}$, Shuang $\mathrm{Li}^{1}$, Ji-Chang Ren ${ }^{1 *}$, Christopher J. Butch ${ }^{2,3 *}$, and Wei Liu ${ }^{1 *}$

${ }^{1}$ Nano and Heterogeneous Materials Center, School of Materials Science and Engineering, Nanjing University of Science and Technology, Nanjing 210094, Jiangsu, China.

${ }^{2}$ Department of Biomedical Engineering, Nanjing University, Nanjing 210023, China.

${ }^{3}$ Blue Marble Space Institute of Science, Seattle, Washington 98154, United States. 


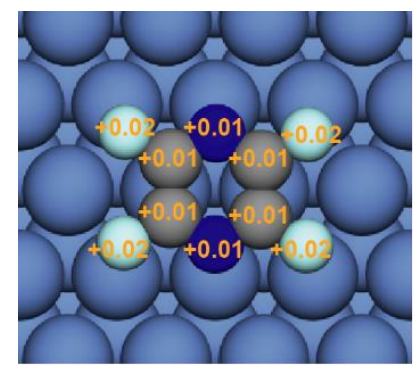

physisorption

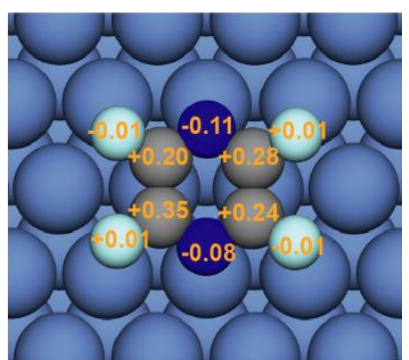

chemisorption

Figure S1 Charge transfer of $\mathrm{C}_{4} \mathrm{~N}_{2} \mathrm{~F}_{4}$ after adsorption on $\mathrm{Ni}(111)$ at physisorbed and chemisorbed states based on Bader charge analysis. The values are positive when the atoms accept electrons, otherwise they are negative. For both the two states, the molecule accepts electrons from the $\mathrm{Ni}(111)$ surface ( 0.14 electrons at the physisorbed state and 0.88 electrons at the chemisorbed state). 

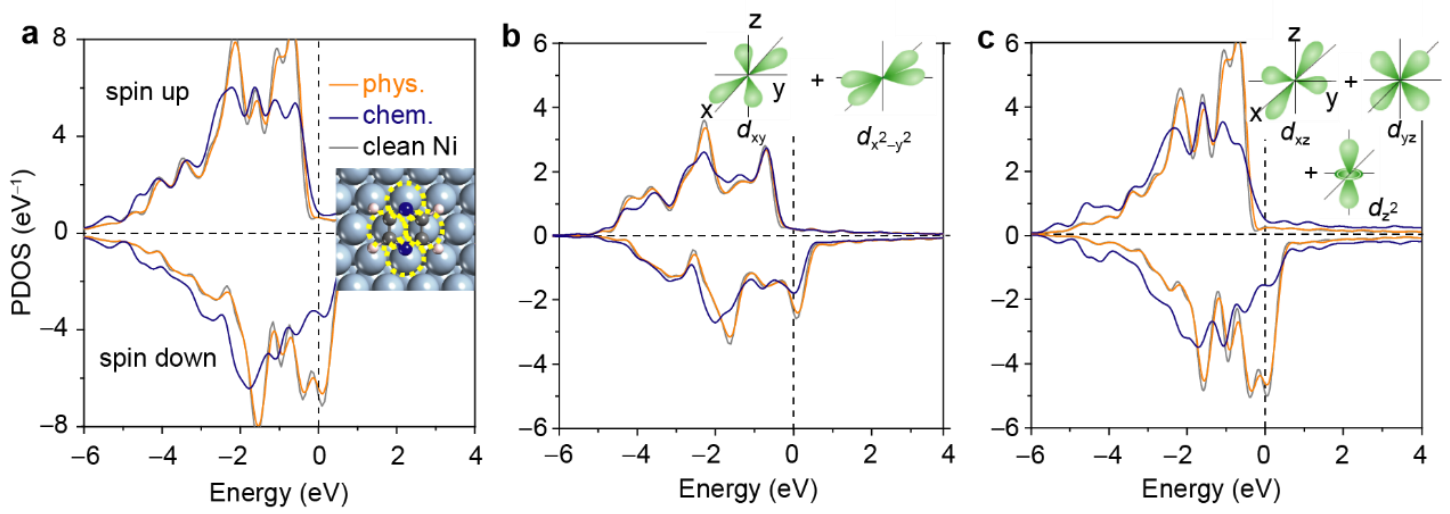

Figure S2 (a) Total projected density of states, (b) $d_{x y}+d_{x^{2}-y^{2}}$ portion, and (c) $d_{\mathrm{xz}}+d_{\mathrm{yz}}+d_{\mathrm{z}^{2}}$ portion of the four Ni atoms (yellow line circled) beneath the adsorbates for physisorbed (orange) and chemisorbed (blue) $\mathrm{C}_{4} \mathrm{~N}_{2} \mathrm{~F}_{4} / \mathrm{Ni}(111)$ systems. The gray lines represent the density of states of the clean $\mathrm{Ni}(111)$ surface. 

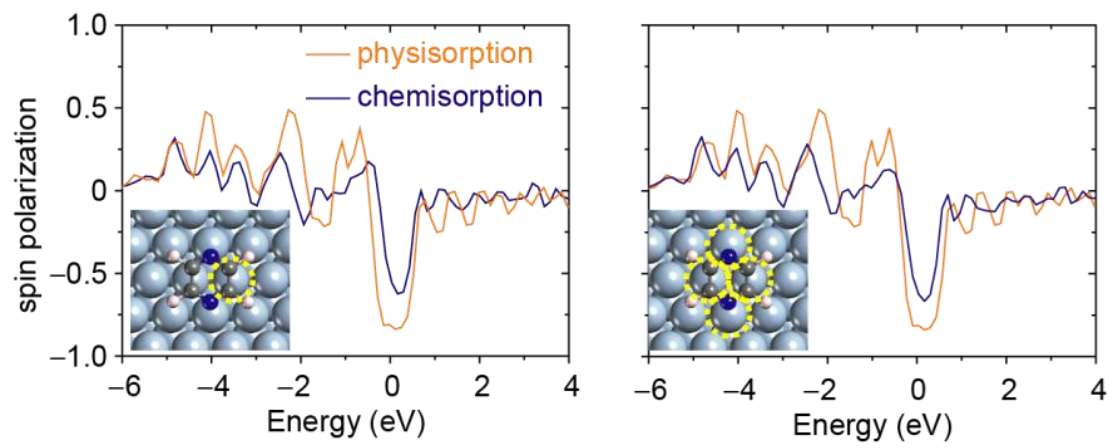

Figure S3 Spin polarization of the density of states of the Ni atoms beneath the carbon atoms (a) and molecules (b). The spin polarization is calculated by $\left(\mathrm{N}_{\uparrow}-\mathrm{N}_{\downarrow}\right) /\left(\mathrm{N}_{\uparrow}-\mathrm{N}_{\downarrow}\right)$, where $\mathrm{N}_{\uparrow(\downarrow)}$ represents the spin-up (spin down) density of states at a specific energy level. 

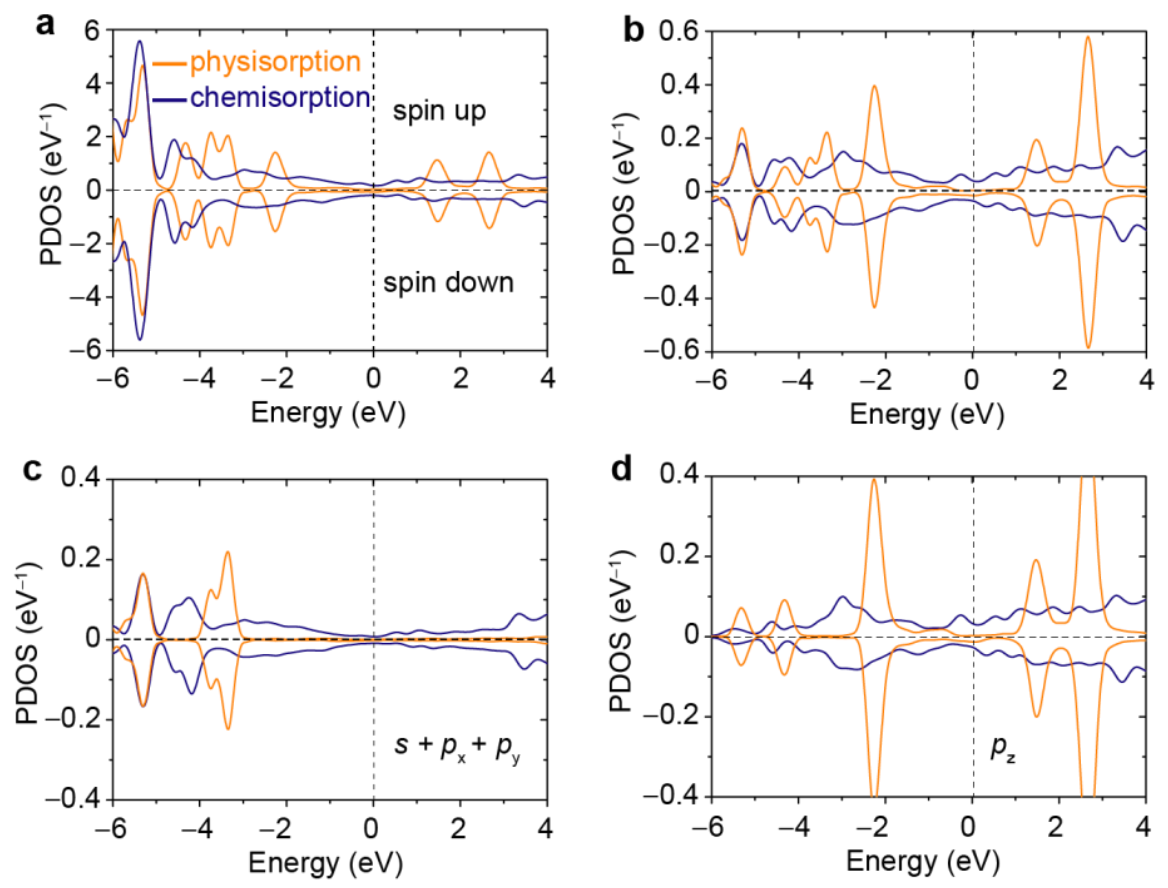

Figure S4 (a) Spin-resolved projected density of states of chemisorbed (blue) and physisorbed (orange) $\mathrm{C}_{4} \mathrm{~N}_{2} \mathrm{~F}_{4}$ molecule on $\mathrm{Ni}(111)$. (b)-(d) Total projected density of states, $s+p_{x}+p_{y}$ portion and $p_{z}$ portion of the $\mathrm{C}$ atoms on the top of $\mathrm{Ni}_{\mathrm{B}}$ atom for physisorbed (orange) and chemisorbed (blue) $\mathrm{C}_{4} \mathrm{~N}_{2} \mathrm{~F}_{4} / \mathrm{Ni}(111)$ systems. 
a
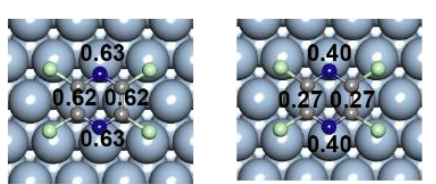

$2.94 \AA$



b
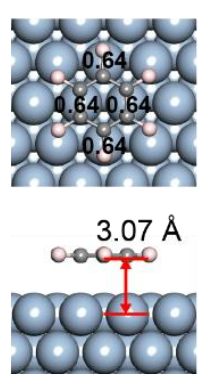

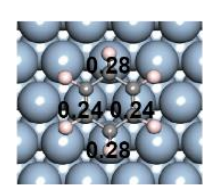

$1.96 \AA$

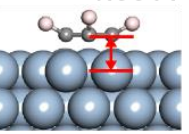

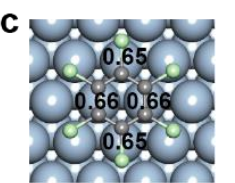
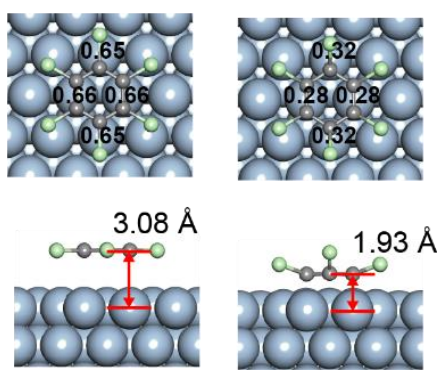

Figure S5 Configurations and atomic magnetic moments (in $\mu_{\mathrm{B}}$ ) of surface Ni atoms for $\mathrm{C}_{4} \mathrm{~N}_{2} \mathrm{Cl}_{4}, \mathrm{C}_{6} \mathrm{~F}_{6}$, and $\mathrm{C}_{6} \mathrm{Cl}_{6}$ on $\mathrm{Ni}(111)$ at physisorbed and chemisorbed states, respectively. 
a
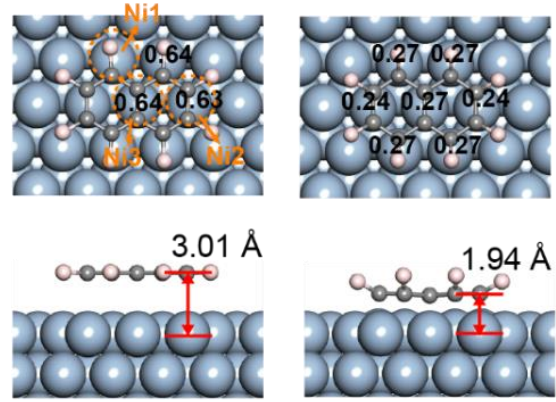

C
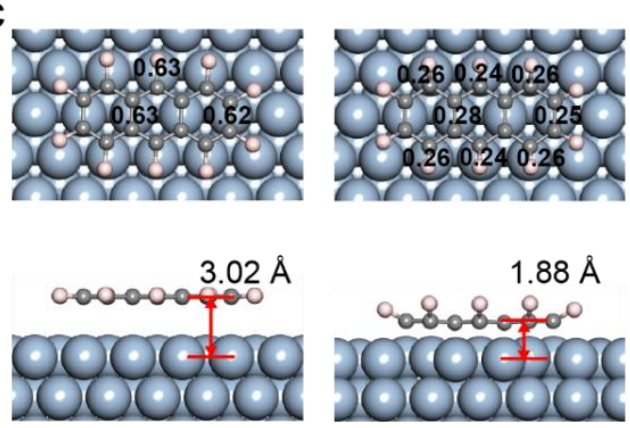

b


d
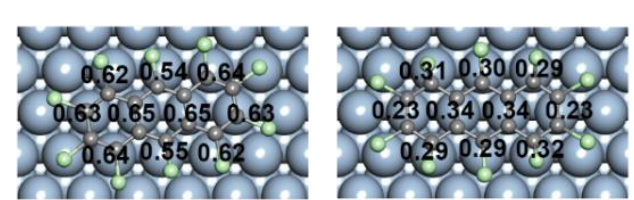

$3.10 \AA$

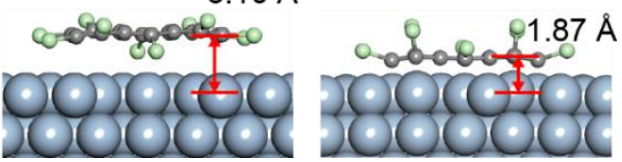

Figure S6 Configurations and atomic magnetic moments of surface $\mathrm{Ni}$ atoms for $\mathrm{C}_{10} \mathrm{~F}_{8}$, $\mathrm{C}_{10} \mathrm{Cl}_{8}, \mathrm{C}_{14} \mathrm{Cl}_{10}$, and $\mathrm{C}_{14} \mathrm{Cl}_{10}$ on $\mathrm{Ni}(111)$ at physisorbed and chemisorbed states, respectively. 




Figure S7 (a) Binding energies of $\mathrm{C}_{4} \mathrm{~N}_{2} \mathrm{~F}_{4}, \mathrm{C}_{4} \mathrm{~N}_{2} \mathrm{Cl}_{4}$, and $\mathrm{C}_{6} \mathrm{Cl}_{6}$ on $\mathrm{Ni}(111)$ as a function of adsorption height of carbon atoms. The energy barriers from the physisorbed state to the chemisorbed state are presented. The $z$ coordinates of carbon atoms were constrained during geometry relaxations while the rest atoms were fully relaxed. The switching barrier between the two spinterfacial states can be tuned by modifying the adsorbate. 

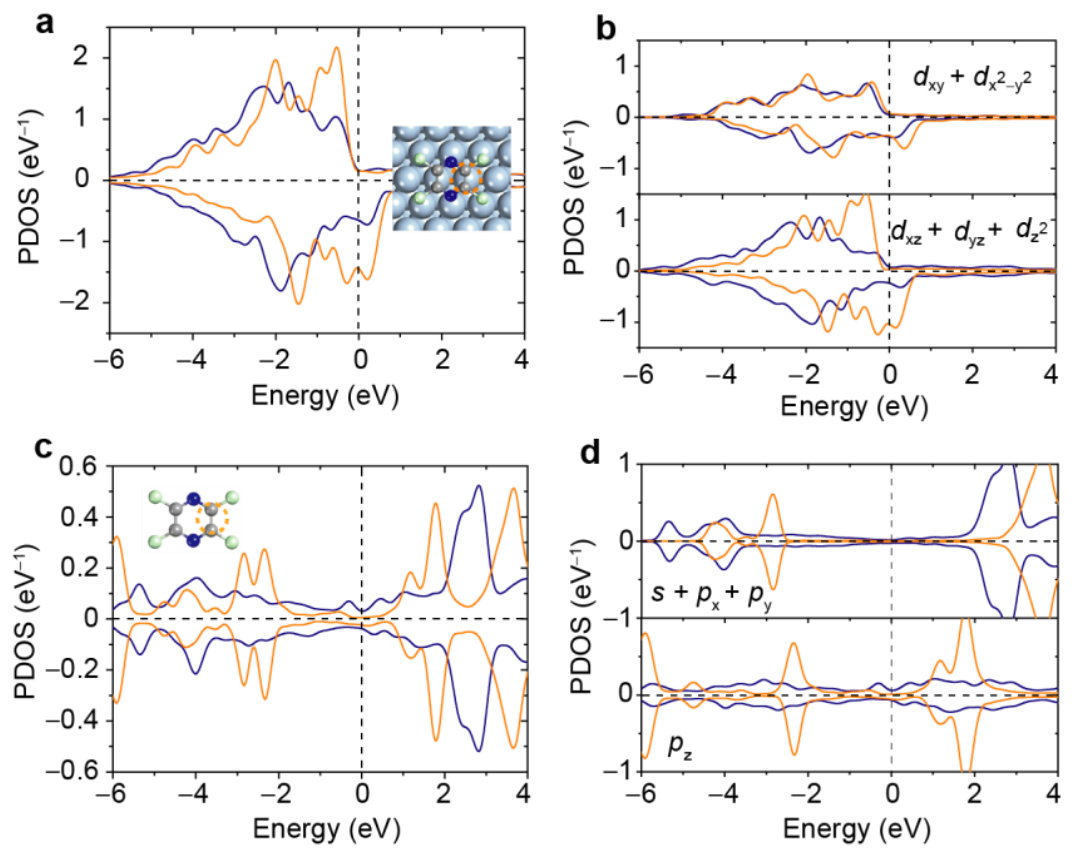

Figure S8 (a) Total projected density of states, (b) $d_{x y}+d_{x 2-y 2}$ portion (upper panel) and $d_{x z}+d_{y z}+d_{z 2}$ portion (lower panel) of the $\mathrm{Ni}$ atoms (orange line circled) below the carbon atoms, (c) total projected density of states, and (d) $s+p_{x}+p_{y}$ portion and $p_{z}$ portion of the $\mathrm{C}$ atoms on the top of $\mathrm{Ni}_{\mathrm{B}}$ atom for physisorbed (orange) and chemisorbed (blue) $\mathrm{C}_{4} \mathrm{~N}_{2} \mathrm{Cl}_{4} / \mathrm{Ni}(111)$ systems. 

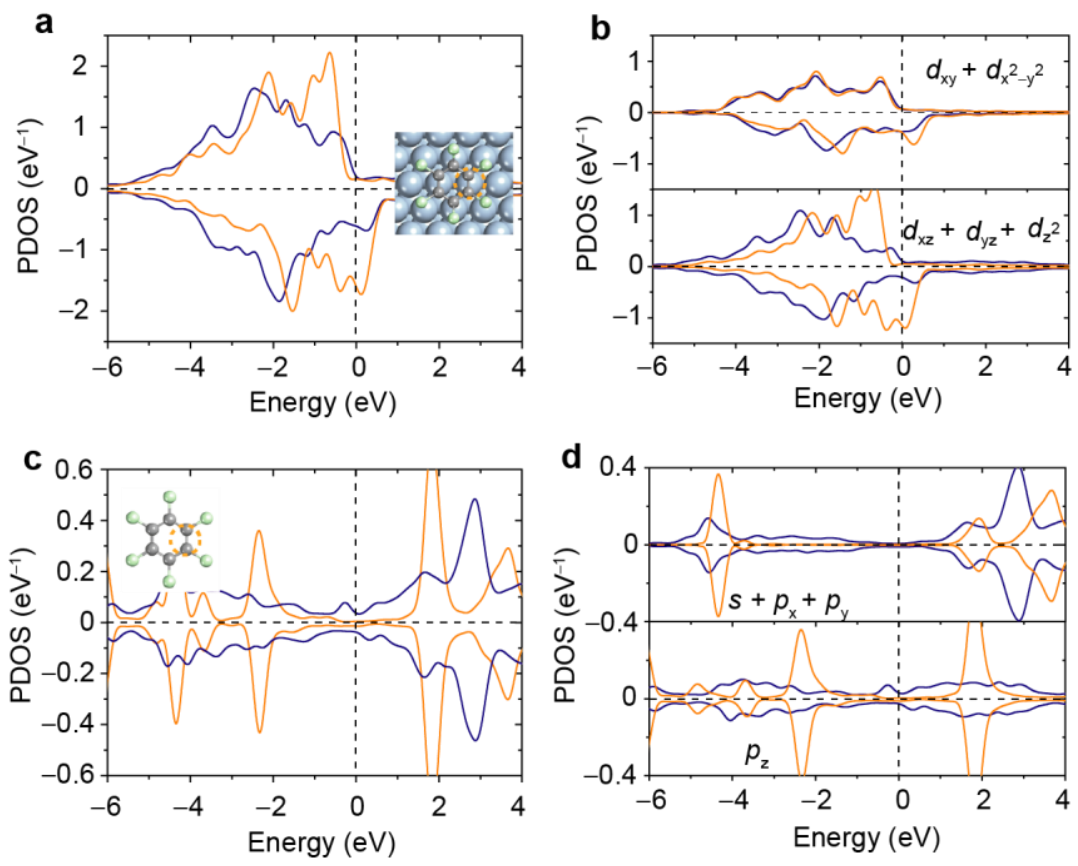

Figure S9 (a) Total projected density of states, (b) $d_{\mathrm{xy}}+d_{\mathrm{x} 2-\mathrm{y} 2}$ portion (upper panel) and $d_{\mathrm{xz}}+d_{\mathrm{yz}}+d_{\mathrm{zz}}$ portion (lower panel) of the $\mathrm{Ni}$ atoms (orange line circled) below the carbon atoms, (c) total projected density of states, and (d) $s+p_{x}+p_{y}$ portion and $p_{z}$ portion of the $\mathrm{C}$ atoms on the top of $\mathrm{Ni}_{\mathrm{B}}$ atom for physisorbed (orange) and chemisorbed (blue) $\mathrm{C}_{6} \mathrm{Cl}_{6} / \mathrm{Ni}(111)$ systems. 
a

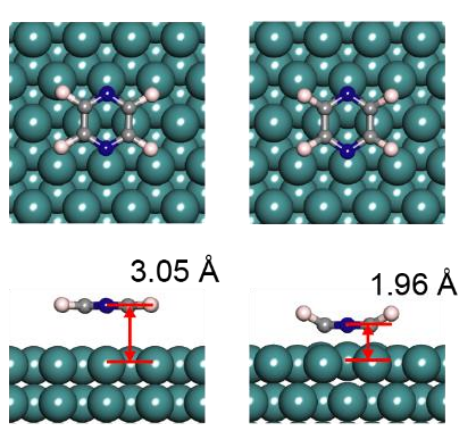

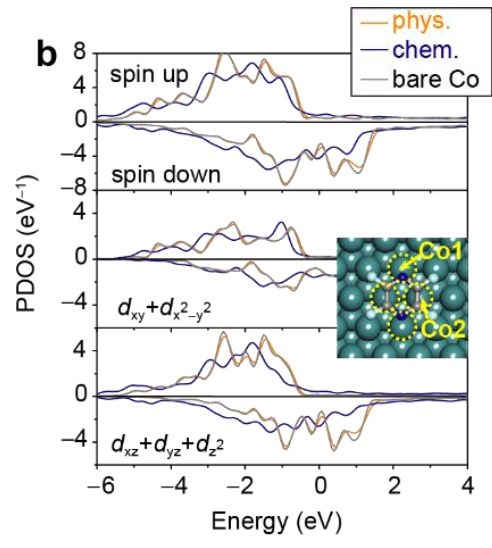

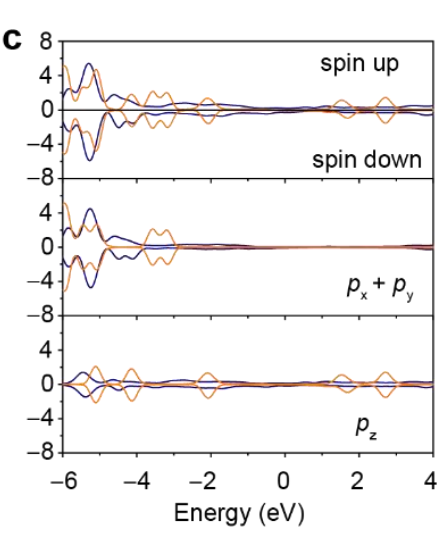

Figure S10 (a) Configurations of $\mathrm{C}_{4} \mathrm{~N}_{2} \mathrm{~F}_{4}$ on $\mathrm{Co}(111)$ at physisorbed (left) and chemisorbed (right) states. (b) Total (upper), in-plane (middle), and out-of-plane (lower) projected density of states of the four Co atoms (yellow circle) under the molecules for clean (gray), physisorbed (orange), and chemisorbed (blue) Co(111) surfaces. (c) Projected density of states of the molecules at the physisorbed (orange) and chemisorbed (blue) states. 
a
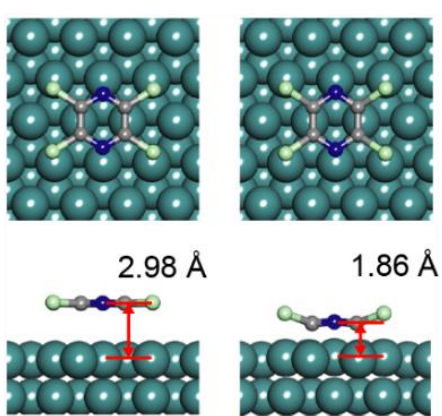

b
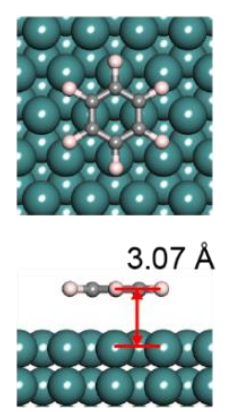

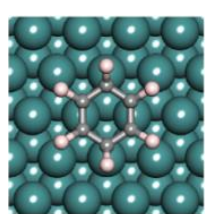

$1.96 \AA$
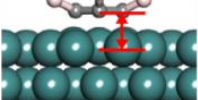

Figure S11 Configurations of $\mathrm{C}_{4} \mathrm{~N}_{2} \mathrm{Cl}_{4}$ and $\mathrm{C}_{6} \mathrm{~F}_{6}$ on $\mathrm{Co}(111)$ at physisorbed and chemisorbed states. 

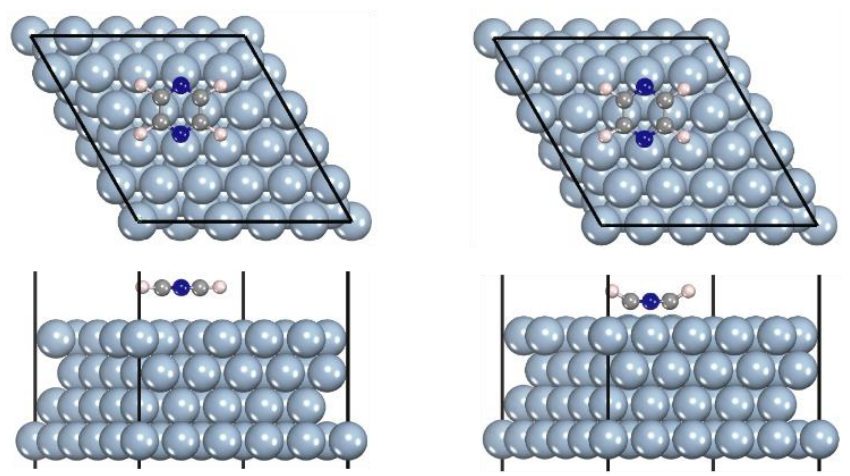

$E_{\text {ads }}=-0.72 \mathrm{eV}$

$E_{\text {ads }}=-1.15 \mathrm{eV}$

Physisorption

Chemisorption

Figure S12 Structure and adsorption energies of physisorbed and chemisorbed states of $\mathrm{C}_{4} \mathrm{~N}_{2} \mathrm{~F}_{4}$ on $\mathrm{Ni}(111)$ with a $5 \times 5$ supercell. 


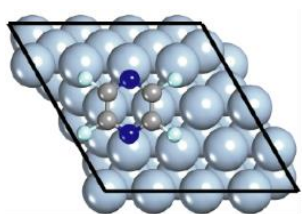

bridge

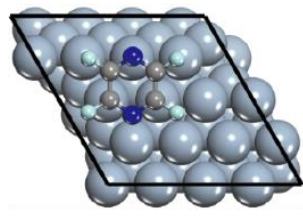

hcp

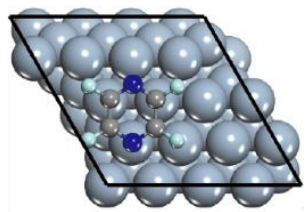

fcc

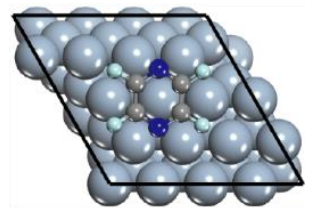

top

Figure S13 Four high-symmetry starting geometries for $\mathrm{C}_{4} \mathrm{~N}_{2} \mathrm{~F}_{4}$ on $\mathrm{Ni}(111)$, termed as "bridge", "hcp", "fcc", and "top", respectively. 

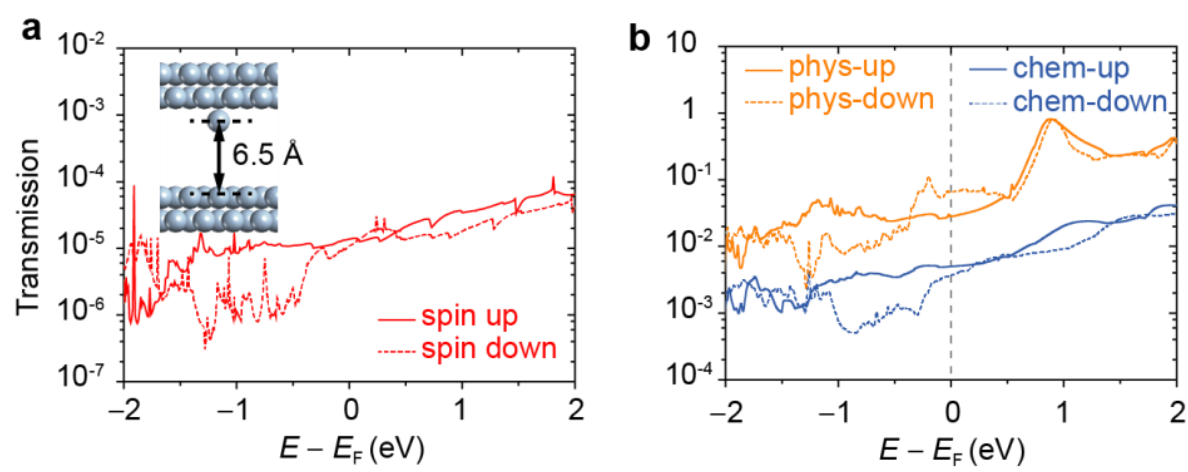

Figure S14 (a) Spin-resolved transmissions of the system without the molecule using a single- $\zeta$-polarized basis set in ATK. (b) Spin-resolved transmissions of $\mathrm{C}_{4} \mathrm{~N}_{2} \mathrm{~F}_{4} / \mathrm{Ni}(111)$ system at the chemisorbed (blue) and physisorbed (orange) states using a double- $\zeta-$ polarized basis set in ATK. 
Table S1 Band centers (in $\mathrm{eV})$ of $s p\left(\varepsilon_{\mathrm{sp}}\right)$ and $d\left(\varepsilon_{\mathrm{d}}\right)$ orbitals and spin-split energies $\left(E_{\mathrm{ss}}\right.$, in $\mathrm{eV}$ ) of the $\mathrm{Ni}$ atoms in clean $\mathrm{Ni}(111)$ surface, $\mathrm{Ni}$ bulk, and bistable adsorption systems of $\mathrm{C}_{4} \mathrm{~N}_{2} \mathrm{~F}_{4}, \mathrm{C}_{4} \mathrm{~N}_{2} \mathrm{Cl}_{4}$, and $\mathrm{C}_{6} \mathrm{Cl}_{6}$ on $\mathrm{Ni}(111)$.

\begin{tabular}{|c|c|c|c|c|c|c|c|c|c|c|c|c|c|}
\hline & \multicolumn{2}{|c|}{$\varepsilon_{s p}$} & \multirow{2}{*}{$\mathrm{ss}$} & \multicolumn{2}{|c|}{$\varepsilon_{d}$} & \multirow{2}{*}{ 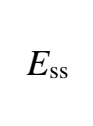 } & \multicolumn{2}{|c|}{$\varepsilon_{d}\left(\mathrm{~d}_{\sigma}\right)$} & \multirow{2}{*}{ ss } & \multicolumn{2}{|c|}{$\varepsilon_{d}\left(\mathrm{~d}_{\pi}\right)$} & \multirow{2}{*}{$E_{\mathrm{ss}}$} \\
\hline & & up & down & & up & down & & up & down & & up & down & \\
\hline Clean s & urface & -0.05 & 0.01 & 0.06 & -1.58 & -0.89 & 0.69 & -1.69 & -0.96 & 0.73 & -1.51 & -0.85 & 0.66 \\
\hline $\mathrm{Bu}$ & & 2.70 & 2.71 & 0.01 & -1.11 & -0.47 & 0.64 & -1.30 & -0.67 & 0.63 & -0.98 & -0.34 & 0.64 \\
\hline \multirow{2}{*}{$\mathrm{C}_{4} \mathrm{~N}_{2} \mathrm{~F}_{4}$} & Phys & 0.18 & 0.17 & 0.01 & -1.24 & -0.70 & 0.55 & -1.59 & -0.90 & 0.69 & -1.45 & -0.83 & 0.62 \\
\hline & Chem & -1.20 & -1.36 & 0.16 & -1.63 & -1.37 & 0.26 & -1.59 & -1.27 & 0.32 & -1.73 & -1.44 & 0.29 \\
\hline \multirow{2}{*}{$\mathrm{C}_{4} \mathrm{~N}_{2} \mathrm{Cl}_{4}$} & Phys & -0.09 & -0.09 & 0 & -1.20 & -0.66 & 0.54 & -1.51 & -0.84 & 0.67 & -1.36 & -0.75 & 0.61 \\
\hline & Chem & -1.72 & -1.70 & 0.02 & -1.76 & -1.50 & 0.26 & -1.67 & -1.34 & 0.33 & -1.83 & -1.54 & 0.29 \\
\hline \multirow{2}{*}{$\mathrm{C}_{6} \mathrm{Cl}_{6}$} & Phys & -0.03 & -0.10 & 0.07 & -1.30 & -0.76 & 0.54 & -1.62 & -0.94 & 0.68 & -1.48 & -0.85 & 0.63 \\
\hline & Chem & -1.75 & -1.76 & 0.01 & -1.79 & -1.55 & 0.24 & -1.67 & -1.37 & 0.30 & -1.88 & -1.61 & 0.27 \\
\hline
\end{tabular}


Table S2. Adsorption heights $h_{\mathrm{C}}$ (in $\AA$ ), adsorption energies $E_{\text {ads }}$ (in $\mathrm{eV}$ ), atomic magnetic moments $\mu_{\mathrm{Ni}}$ (in $\mu_{\mathrm{B}}$ ) of atom $\mathrm{Ni}$ atoms below the $\mathrm{C}-\mathrm{C}$ bond, and integrated magnetic moments $\mu_{\mathrm{mol}}$ (in $\mu_{\mathrm{B}}$ ) of molecules for various halogenated aromatic hydrocarbons on $\mathrm{Ni}(111)$ at chemisorption and physisorption states, respectively (structure details refer to Figures S5-S7).

\begin{tabular}{ccccccccc}
\hline \multirow{3}{*}{ molecule } & \multicolumn{3}{c}{ physisorption } & \multicolumn{5}{c}{ chemisorption } \\
\cline { 2 - 8 } & $h_{\mathrm{C}}$ & $E_{\text {ads }}$ & $\mu_{\mathrm{Ni}}$ & $\mu_{\mathrm{mol}}$ & $h_{\mathrm{C}}$ & $E_{\text {ads }}$ & $\mu_{\mathrm{Ni}}$ & $\mu_{\mathrm{mol}}$ \\
\hline $\mathrm{C}_{4} \mathrm{~N}_{2} \mathrm{~F}_{4}$ & 3.05 & -0.73 & 0.62 & -0.01 & 1.98 & -1.18 & 0.27 & -0.05 \\
$\mathrm{C}_{4} \mathrm{~N}_{2} \mathrm{Cl}_{4}$ & 2.94 & -1.26 & 0.62 & -0.02 & 1.92 & -1.90 & 0.27 & -0.01 \\
$\mathrm{C}_{6} \mathrm{~F}_{6}$ & 3.07 & -0.93 & 0.64 & 0 & 1.96 & -1.63 & 0.24 & -0.04 \\
$\mathrm{C}_{6} \mathrm{Cl}_{6}$ & 3.08 & -1.56 & 0.66 & -0.01 & 1.93 & -2.11 & 0.28 & -0.01 \\
$\mathrm{C}_{10} \mathrm{~F}_{8}$ & 3.01 & -1.33 & 0.63 & -0.01 & 1.94 & -2.46 & 0.24 & -0.09 \\
$\mathrm{C}_{10} \mathrm{Cl}_{8}$ & 3.02 & -1.99 & 0.63 & -0.02 & 1.92 & -2.89 & 0.25 & -0.04 \\
$\mathrm{C}_{14} \mathrm{~F}_{10}$ & 3.02 & -1.79 & 0.63 & -0.02 & 1.88 & -3.46 & 0.25 & -0.14 \\
$\mathrm{C}_{14} \mathrm{Cl}_{10}$ & 3.10 & -2.49 & 0.64 & -0.04 & 1.87 & -3.90 & 0.23 & -0.05 \\
\hline
\end{tabular}


Table S3 Adsorption heights $h_{\mathrm{C}}$ (in $\AA$ ), adsorption energies $E_{\text {ads }}$ (in $\mathrm{eV}$ ), and atomic magnetic moments (in $\left.\mu_{\mathrm{B}}\right)$ of atom $\operatorname{Co} 1\left(\mu_{1}\right)$ and $\operatorname{Co} 2\left(\mu_{2}\right)$ and molecules $\left(\mu_{\mathrm{mol}}\right)$ in $\mathrm{C}_{4} \mathrm{~N}_{2} \mathrm{~F}_{4}, \mathrm{C}_{4} \mathrm{~N}_{2} \mathrm{Cl}_{4}$, and $\mathrm{C}_{6} \mathrm{~F}_{6}$ on $\mathrm{Co}(111)$ at chemisorbed and physisorbed states, respectively.

\begin{tabular}{ccccccccccc}
\hline & \multicolumn{4}{c}{ physisorption } & \multicolumn{5}{c}{ chemisorption } \\
\cline { 2 - 11 } molecule & $h_{\mathrm{C}}$ & $E_{\text {ads }}$ & $\mu_{1}$ & $\mu_{2}$ & $\mu_{\text {mol }}$ & $h_{\mathrm{C}}$ & $E_{\text {ads }}$ & $\mu_{1}$ & $\mu_{2}$ & $\mu_{\text {mol }}$ \\
\hline $\mathrm{C}_{4} \mathrm{~N}_{2} \mathrm{~F}_{4}$ & 3.05 & -0.54 & 1.74 & 1.71 & 0 & 1.96 & -1.26 & 1.43 & 0.95 & -0.16 \\
$\mathrm{C}_{4} \mathrm{~N}_{2} \mathrm{Cl}_{4}$ & 2.98 & -0.83 & 1.74 & 1.70 & 0.01 & 1.86 & -1.77 & 1.47 & 0.89 & -0.10 \\
$\mathrm{C}_{6} \mathrm{~F}_{6}$ & 3.07 & -0.72 & 1.74 & 1.73 & 0 & 1.96 & -1.62 & 1.29 & 0.86 & -0.23 \\
\hline
\end{tabular}

